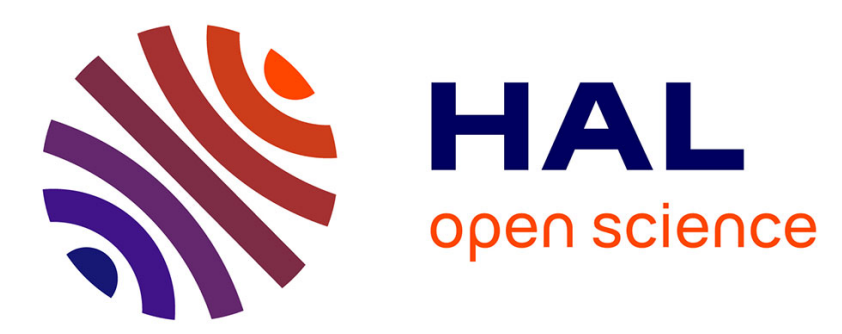

\title{
Plasma Electrolytic Oxidation of Aluminium Networks to form a Metal-Cored Ceramic Composite Hybrid Material
}

\author{
Cs. Dunleavy, Ja. Curran, Tw. Clyne
}

\section{- To cite this version:}

Cs. Dunleavy, Ja. Curran, Tw. Clyne. Plasma Electrolytic Oxidation of Aluminium Networks to form a Metal-Cored Ceramic Composite Hybrid Material. Composites Science and Technology, 2011, 71 (6), pp.908. 10.1016/j.compscitech.2011.02.007 . hal-00736291

\section{HAL Id: hal-00736291 \\ https://hal.science/hal-00736291}

Submitted on 28 Sep 2012

HAL is a multi-disciplinary open access archive for the deposit and dissemination of scientific research documents, whether they are published or not. The documents may come from teaching and research institutions in France or abroad, or from public or private research centers.
L'archive ouverte pluridisciplinaire HAL, est destinée au dépôt et à la diffusion de documents scientifiques de niveau recherche, publiés ou non, émanant des établissements d'enseignement et de recherche français ou étrangers, des laboratoires publics ou privés. 


\section{Accepted Manuscript}

Plasma Electrolytic Oxidation of Aluminium Networks to form a Metal-Cored Ceramic Composite Hybrid Material

CS. Dunleavy, JA. Curran, TW. Clyne

PII: S0266-3538(11)00074-1

DOI: 10.1016/j.compscitech.2011.02.007

Reference: CSTE 4932

To appear in: Composites Science and Technology

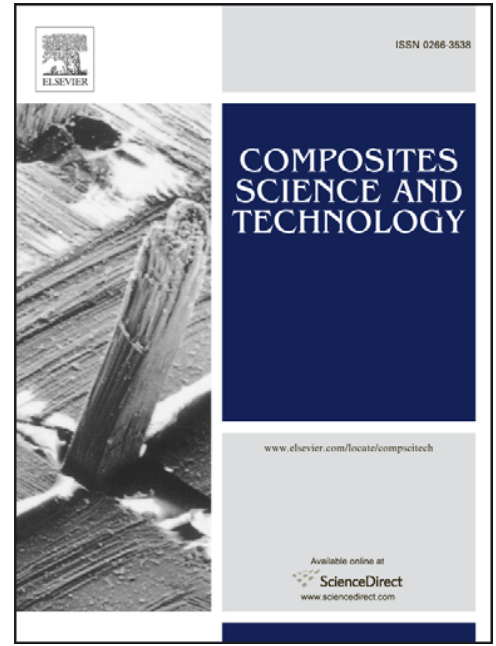

Received Date: $\quad 19$ July 2010

Revised Date: $\quad 11$ January 2011

Accepted Date: $\quad 14$ February 2011

Please cite this article as: Dunleavy, CS., Curran, JA., Clyne, TW., Plasma Electrolytic Oxidation of Aluminium Networks to form a Metal-Cored Ceramic Composite Hybrid Material, Composites Science and Technology(2011), doi: 10.1016/j.compscitech.2011.02.007

This is a PDF file of an unedited manuscript that has been accepted for publication. As a service to our customers we are providing this early version of the manuscript. The manuscript will undergo copyediting, typesetting, and review of the resulting proof before it is published in its final form. Please note that during the production process errors may be discovered which could affect the content, and all legal disclaimers that apply to the journal pertain. 


\title{
Plasma ElECTROLYTIC OXIDATION OF AluminiUM NeTWORKS TO FORM A METAL-CORED CERAMIC COMPOSITE HYBRID MATERIAL
}

\author{
CS Dunleavy, JA Curran \& TW Clyne \\ Department of Materials Science \& Metallurgy \\ Cambridge University \\ Pembroke Street, Cambridge CB2 3QZ, UK
}

\begin{abstract}
A commercially-available low density aluminium network material ("Duocel”) has been processed by plasma electrolytic oxidation to produce a ceramic hybrid material comprising an assembly of ceramic struts with metallic cores. The architecture and microstructure of this material were studied using X-ray tomography, scanning electron microscopy and densitometry. Conversion fractions were determined from mass gains and by image analysis of cross-sections, and the ceramic density was evaluated by hydrostatic weighing. Tensile and compressive testing of the hybrid material was used to study the toughness, as a function of the conversion fraction. Such material retains some of the beneficial mechanical properties of a metal (ductility and toughness), while also exhibiting a low overall density and a high specific surface area of ceramic. It can thus be considered as a highly permeable ceramic scaffold, with a relatively high toughness.
\end{abstract}

Keywords:

A: Coating

A: Hybrid composites

A: Layered structures

B: Fracture toughness

B: Surface treatments

\section{Introduction}

Metallic foams can offer useful property combinations, with low density and/or high specific surface area often being beneficial [1]. Furthermore, they often exhibit relatively high stiffnesses, particularly the flexural rigidity, and certain types of foam can absorb significant amounts of energy during plastic deformation [2-4]. Ceramic surface coatings are often applied to metals to improve their resistance to aqueous corrosion, as well as their tribological properties. They may also offer high specific surface area, and thus be useful for applications involving filtration, catalytic action etc. The present paper concerns the scope for producing useful material by controlled oxidation of a particular type of (relatively coarse, high porosity) open cell metallic foam.

There have been various studies [5-7] on the production of highly porous metallic materials incorporating surface oxides. However, none of these production techniques were based on plasma electrolytic oxidation (PEO), a process being increasingly used to create relatively thick oxide layers on the surfaces of aluminium, magnesium and titanium alloys [8-12]. Since these coatings are created by electrolytic immersion, the process can readily be applied to the surfaces of complex, re-entrant shapes such as highly porous foams. On aluminium, the process generates a layer of partially-crystalline alumina [13], which can enhance wear and corrosion protection, as well as presenting a thermal barrier [14] and providing a porous surface [15], well- 
suited to keying of paint layers etc. Furthermore, the porosity in PEO coatings tends to be very fine and highly inter-connected [15], so that a large specific surface area is expected, which could be enhanced if the substrate were itself a foam or network of some kind. This offers scope for the creation of material exhibiting a very large ceramic surface area, in combination with a residual metallic core network that confers toughness. There are many potential applications for such material.

In the present work, a hybrid material of this type, comprising a ceramic network with residual metallic reinforcement in the core of the struts, has been produced by treating an opencelled Duocel ${ }^{\mathrm{TM}}$ aluminium network material with the Keronite ${ }^{\mathrm{TM}}$ PEO process. An outline is given of the processing involved and the microstructure exhibited by the hybrid material. Some simple mechanical characteristics are then investigated, which are of relevance to its practical use.

\section{Experimental Procedures}

\subsection{Aluminium Network Material}

A commercially-available aluminium network material (Duocel ${ }^{\mathrm{TM}}$, produced by ERG Materials and Aerospace Corporation, Oakland, California) was used in the current work. This is composed of 6106-T6 aluminium alloy, in the form of a coarse, highly porous network. Several grades are available, with a range of cell coarseness, all of which have an approximate average density of $0.25 \mathrm{Mg} \mathrm{m}^{-3}$, corresponding to a "porosity" level of about $90 \%$. Details of how the material is manufactured can be found on the website of the supplier [16]. The work described here was all carried out with the grade described as "20 pores per inch". Samples were cut using electro-discharge machining.

The architecture of the foam was characterised by applying X-ray tomography (Skyscan 1072) to four samples, each with dimensions of $1011 \quad 12 \mathrm{~mm}$. The 3-D reconstructions were analysed using 3DMA algorithms [17] to extract statistics on the orientation distribution and length of struts. An estimate of the characteristic diameter of struts was made by analysing the areas of the least elliptical cross-sections (those most likely to represent perpendicular crosssections) in computed X-ray cross sections.

\subsection{PEO Processing}

A commercially-available PEO process was employed, namely Keronite ${ }^{\mathrm{TM}} \mathrm{G} 2 \mathrm{~A}$ processing, using a dilute alkaline electrolyte consisting of $1.5 \mathrm{~g} \mathrm{l}^{-1} \mathrm{KOH}$ (Potassium hydroxide), $10 \mathrm{~g} \mathrm{l}^{-1}$ $\mathrm{Na}_{4} \mathrm{P}_{2} \mathrm{O}_{7}$ (Sodium tetrapyrophosphate) and $10 \mathrm{~g} \mathrm{l}^{-1} \mathrm{Na}_{2} \mathrm{SiO}_{3}$ (Sodium silicate). A $10 \mathrm{~kW}$ Keronite "Generation 2" (50 Hz AC) power supply was used, with the supply capacitance set so as to achieve an initial current of density $15 \mathrm{~A} \mathrm{dm}^{-2}$. (Similar current densities are typically used in the processing of bulk aluminium.) The initial current was set to 2.7 A, 4.9 A and 7.7 A respectively for the tomography, compression, and tension test pieces. Electrical connections were made by spark welding four aluminium wires to the end of each sample, shielding the wires with plastic tubing and a silicon rubber seal.

All specimens were cut to shape prior to PEO processing, which was therefore carried out on samples with a range of linear dimensions, most of them of the order of $10 \mathrm{~mm}$. Several different processing times were used, ranging from 50 to 180 minutes, so as to achieve different conversion fractions of the aluminium (see §2.3). After processing, each sample was washed for 
3 minutes under running tap-water, and then for 10 minutes in an ultrasonic bath, in order to remove any electrolyte residue.

\subsection{Characterisation of PEO Coatings}

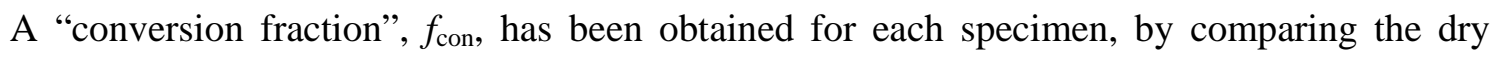
sample mass before and after processing. It is defined as the mass fraction of aluminium from the substrate that becomes converted to ceramic. It can be shown that its value can be expressed as

$$
f_{\text {con }}=\left(\frac{m_{\mathrm{a}}-m_{0}}{m_{0}}\right)\left(\frac{2 M[\mathrm{Al}]}{3 M[\mathrm{O}]}\right)
$$

where $m_{0}$ and $m_{\mathrm{a}}$ are the masses of the sample before and after PEO processing and $M[\mathrm{Al}], M[\mathrm{O}]$ are the respective molar masses of aluminium and oxygen. This assumes that the increase in the mass of the sample is caused only by the incorporation of oxygen into the ceramic layer, and that the ceramic formed is stoichiometric $\mathrm{Al}_{2} \mathrm{O}_{3}$.

The density of the ceramic coatings was determined by using a Sartorius microbalance to compare the weights of the coated samples in air and when immersed in a dense, low viscosity liquid (Flutec ${ }^{\mathrm{TM}}, \mathrm{C}_{11} \mathrm{~F}_{20}$, with a density of $1.9 \mathrm{Mg} \mathrm{m}^{-3}$ ). This was done after surface sealing of the ceramic specimens being achieved with a lacquer, the weight of this sealant being taken into account in the analysis.

Twelve samples were mounted in resin, ground (using standard metallographic procedures, employing silicon carbide papers up to a final stage of 2500 grit), producing cross sections for image analysis. Images were recorded using an optical microscope and digital camera, and analysed using ImageJ ${ }^{\mathrm{TM}}$ software, to estimate the average coating thickness and total volume fraction, based on observed average values for strut radius before and after coating, and conversion radius after coating.

For more detailed examination of the microstructure of the PEO layer, three mounted sections were polished with $1 \mu \mathrm{m}$ diamond paste, sputtered with a thin gold layer to eliminate charging, and examined using a JEOL-5800 LV SEM, in backscattered mode. Un-mounted samples were also examined in the SEM, in secondary electron mode.

\subsection{Mechanical Testing}

\subsubsection{Compression Testing}

Nine samples of hybrid material were tested, together with three samples of as-received Duocel. The loading arrangement is illustrated in Fig.1. Pressure was applied over the $2020 \mathrm{~mm}$ face, using an ESH $10 \mathrm{kN}$ servo-hydraulic machine with a $2.5 \mathrm{kN}$ load cell and a displacement rate of $0.05 \mathrm{~mm} \mathrm{~min}^{-1}$. Displacement was measured between the two parallel plates of the compression piston, using an LVDT.

\subsubsection{Tensile Testing}

Twelve samples of hybrid material were tested in tension, together with four untreated samples of Duocel. The same loading arrangement and displacement rate were employed as for compressive testing. For the tensile testing, however, the samples were of dog-bone geometry, 
with $10 \mathrm{~mm}$ square sections and a $30 \mathrm{~mm}$ gauge length. The ends were impregnated with acrylic resin, to provide support for clamping and to prevent local deformation at the gripping points.

\section{Architecture and Microstructure}

\subsection{Architecture of As-received Duocel Material}

An X-ray tomographic visualisation of the starting material is shown in Fig.2(a), while Fig.2(b) illustrates typical strut orientations and lengths obtained from such data. A measured distribution of strut lengths, compiled from tomography data for four samples, is shown in Fig.3(a). An orientation distribution for the angle between strut axes and a reference direction is presented in Fig.3(b), where it can be seen that the material is approximately isotropic. The mean strut length is $1900 \pm 700 \mu \mathrm{m}$, where the uncertainty quoted is the square root of the distribution variance. The mode value for the co-ordination number of vertices was 4 . While the "cell size" is a little difficult to define and measure, it is typically of the order of 1-2 mm.

\subsection{Coating Surface Morphology and Microstructure}

Fig.4 shows an SEM (secondary electron) image of one of the vertices (with a connectivity of four), after PEO processing to give $f_{\text {con }}=0.272$, together with a higher magnification image having typical surface features highlighted. The images confirm that the surface appearance is similar to that observed on the (comparable) bulk alloy AA6082, after being processed in a similar way [13]. The surface is rough, with various scales of porosity, including crater-like features - see the highlighted areas (b) and (c) in Fig.5 - which are suggestive of melt flow and solidification. Other characteristic features, such as those marked (a) and (d), are also visible.

Fig.5 shows a set of (backscattered) SEM images of typical strut cross-sections, for specimens with conversion fraction values of $0.293,0.412$ and 0.540 . The coatings exhibit a fairly clear two-layer structure, similar [13] to that produced on bulk AA6082. The inner layer (possibly corresponding to material below the original free surface of the starting material) exhibits finescale $(\sim \mu \mathrm{m}$ or sub- $\mu \mathrm{m})$ porosity throughout, whilst the outer layer consists of apparently fairly dense material containing dispersions of much coarser (tens of $\mu \mathrm{m}$ ) pores. Such features can be explained, at least approximately, in terms of various phenomena that occur during PEO processing [15].

\subsection{Conversion Fraction Values}

Measured values of $f_{\text {con }}$, obtained for various specimens produced for purposes of mechanical testing, are plotted in Fig.6(a) as a function of the processing time. It can be seen that the conversion of metal to ceramic proceeds at an approximately linear rate and can generate specimens with high fractions of ceramic - at least up to around $90 \%$. Of course, as this value approaches $100 \%$, electrical connectivity throughout the metallic core network will eventually be lost and the process will slow down and stop. Nevertheless, it's clear that, by simply varying the processing time, it's possible to produce material with a wide range of residual metallic core content. Furthermore, at least for starting material with the structure of Duocel, and for specimens in this size range, the structure is approximately uniform throughout - for example, the thickness of the ceramic coating does not noticeably vary with distance into the "interior" of the specimens. In fact, it is well known that PEO tends to exhibit a good "throwing power", so that uniform coating thickness is obtained within relatively deep re-entrant regions. The peak 
ratio of penetration depth to lateral channel width within these specimens was about 5 and it is thought that this is significantly below the maximum value achievable during PEO processing.

These conversion fraction values, obtained by simple weighing of specimens before and after processing, can be compared with corresponding values obtained by study of transverse sections of struts, based on measurement of the coating thickness and residual core radius, and assumed densities for the two. The comparison is shown in Fig.6(b), in which $f_{\text {con }}$ values obtained using the two techniques are plotted against each other. In general, it is clear that there is a large measure of agreement between the values obtained via the two methods. This comparison can also be used to estimate the effective density of the ceramic. It can be seen in Fig.6(b) that the most appropriate value is apparently about $2.6 \mathrm{Mg} \mathrm{m}^{-3}$. This is consistent with measurements made directly by hydrostatic weighing. The value reflects the presence of substantial levels of porosity, since the nominal density of most alumina phases is about $3.8 \mathrm{Mg} \mathrm{m}^{-3}$.

\section{Mechanical Characteristics}

\subsection{Compressive Loading}

Representative stress-strain curves for specimens with different conversion fractions are shown in Fig.7. The unprocessed $\left(f_{\text {con }}=0\right)$ material shows behaviour characteristic of a (low density) metal foam, with a plateau stress of $\sim 3 \mathrm{MPa}$. The hybrid materials show slightly different behaviour, with peaks at about the same stress, but plateaux developing at progressively lower levels as the conversion fraction rises. The peaks can be attributed to the onset of cracking in the ceramic layers, which fail in a brittle fashion, with the stress then dropping off as these ceramic layers cease to bear load, eventually reaching a plateau corresponding to plastic deformation of the residual aluminium in the cores of the struts. This can occur up to relatively large macroscopic strains, which is encouraging in terms of suggesting that the cores have not become noticeably embrittled, either by the processing itself or as a consequence of the constraint imposed by the enveloping ceramic. This is unsurprising, since the high levels of porosity (both fine and coarse) in the ceramic are expected to confer a relatively low stiffness and hence reduce the constraint on plastic deformation of the metal cores. Of course, compressive loading gives no real indication of the (opening mode) toughness of a material, but the fracture behaviour of these materials in tension is also encouraging (see §4.2).

\subsection{Tensile Loading}

Stress-strain curves for specimens with different conversion fractions are shown in Fig.8. These plots all exhibit a peak corresponding to the onset of fracture. However, while in a monolithic sample this would tend to be followed by either an immediate fall to zero stress or at least a sharp tailing-off in (nominal) stress level as necking takes place, (metallic) network materials tend to exhibit rather different behaviour. The peak corresponds to fracture of (or neck formation at) one or more struts, but not to failure across the complete section of the specimen. The peak therefore tends to be followed by a relatively gradual fall-off in stress and indeed final failure may take place at much larger (nominal) strains than that corresponding to the peak stress. This type of behaviour does, of course, depend on the struts being able to exhibit appreciable ductility. It can be seen that, even for specimens in which much of the strut section has been converted to ceramic, cores continue to deform plastically after some struts have ruptured and much of the ceramic has become heavily cracked. 
Attempting to evaluate the toughness of this type of material in a meaningful way presents challenges, since its high elastic and plastic compliance has the effect of making it difficult to generate well-defined fracture planes and measure the work associated with crack advance. In these tensile tests, the total work done is readily evaluated as the area under the loaddisplacement curve. However, there is clearly a possibility that a significant proportion of this work was not associated with crack propagation. In fact, a previous study of the tensile fracture of metallic fibre network materials [18] indicated that there tends to be a "process zone", having linear dimensions of the order of a few fibre segment lengths, within which most of the total work done during deformation and fracture tends to be dissipated, as plastic deformation becomes concentrated there. Provided that the gauge length is sufficient to encompass the whole of this process zone, and the plastic work done outside the zone is negligible in comparison, then a nominal work of fracture can be obtained on simply dividing the total work by the sectional area of the gauge length. The outcome of this operation is shown in Fig.9, with this nominal fracture energy plotted against the corresponding conversion fraction. The values are likely to be overestimates, since obviously there may be some plastic deformation occurring outside the process zone. However, they are unlikely to be gross overestimates in the present case, since the width of the process zone appeared to be smaller in magnitude than the specimen gauge length (30 mm), and there did not appear to be much plastic deformation occurring outside of this zone, so that at least most of the total work done could be regarded as being associated with the fracture process.

In any event, two points can be noted concerning the plot. Firstly, the approximate magnitude of these fracture energy values (ie a few $\mathrm{kJ} \mathrm{m}^{-2}$ ) represents a respectable toughness appreciably higher (over the range of ceramic proportions created in these specimens), for example, than values expected of most ceramics (porous or fully dense). Secondly, while the fracture energy does, as expected, fall off as the conversion fraction increases, it remains relatively high over a wide range of metal contents. It would appear that significant toughness is conferred by the presence of the metallic cores even when about $60 \%$ of the original metal has been converted to ceramic. This is clearly encouraging from a practical point of view.

\section{Conclusions}

The following conclusions can be drawn from this work:

(a) PEO processing can readily be carried out on aluminium network material so as to create a highly porous composite hybrid. This has been done using "Duocel” based on 6106-T6 alloy, with a cell diameter of the order of $1 \mathrm{~mm}$ and a strut diameter of the order of 200-300 $\mu \mathrm{m}$. The ceramic coating formed (essentially pure alumina) is similar in microstructure to those created on corresponding bulk alloys. It is also similar, in both thickness and microstructure, throughout the network. The limits within which this is the case, in terms of the specimen dimensions beyond which the coating thickness is lower in the interior, have not been explored, but it is already clear that a uniform structure can be created throughout relatively large specimens ( 10 $\mathrm{mm}$ in linear dimensions).

(b) The conversion fraction (ie the proportion of the metal that has been converted to oxide) has been evaluated for a substantial number of specimens. It has been found that hybrid material can be created with values up to about $90 \%$, representing architectures with relatively small residual metal cores throughout the network of struts. This happens despite the fact that there is a substantial variation in the local strut diameter at different locations in the starting material, suggesting that the process takes place such that there 
is a strong tendency for the current density to be uniform throughout the residual metallic network.

(c) Hybrid composite material produced in this way is relatively tough, since the metallic cores tend to exhibit extensive plastic deformation prior to fracture, even when constrained by the surrounding ceramic. Part of the reason for this may be related to the fact that the ceramic exhibits relatively high porosity levels, over a range of scales. The (nominal) fracture energy has been estimated via the work done during tensile failure and values have been obtained in the range of a few $\mathrm{kJ} \mathrm{m}^{-2}$. The value falls off as the conversion fraction is increased, but is still around $1 \mathrm{~kJ} \mathrm{~m}^{-2}$ for a conversion fraction value of about $60 \%$.

\section{Acknowledgements}

Thanks are due to Kevin Roberts for assistance with the PEO processing facilities. Financial support has been received from EPSRC. 


\section{References}

1. Banhart, J, Manufacture, Characterisation and Application of Cellular Metals and Metal Foams. Progress Mater. Sci., 46: (2001) p. 559-632.

2. Sugimura, Y, Meyer, J, He, MY, Bart-Smith, H, Grenestedt, J and Evans, AG, On the Mechanical Performance of Closed Cell Al Alloy Foams. Acta Mater., 45: (1997) p. 5245-5259.

3. Banhart, J and Baumeister, J, Deformation Characteristics of Metal Foams. J. Mater. Sci., 33: (1998) p. 1431-1440.

4. San Marchi, C and Mortensen, A, Deformation of Open-Cell Aluminium Foam. Acta. Mat., 49: (2001) p. 3959-3969.

5. Smorygo, O, Mikutski, V, Leonov, A, Marukovich, A and Vialiuha, Y, Nickel foams with oxidation-resistant coatings formed by combustion synthesis. Scripta Materialia, 58: (2008) p. 910-913.

6. Kolarik, V, Juez-Lorenzo, M, Anchustegui, M and Fietzek, H, Multifunction high temperature coating system based on aluminium particle technology, in HIGH TEMPERATURE CORROSION AND PROTECTION OF MATERIALS 7, PTS 1 AND 2, P Steinmetz, IG Wright, A Galerie, D Monceau and S Mathieu (eds.). 2008, Materials Science Forum, Trans Tech Ltd: Zurich. p. 769-777.

7. Singh, R, Lee, PD, Jones, JR, Poologasundarampillai, G, Post, T, Lindley, TC and Dashwood, RJ, Hierarchically structured titanium foams for tissue scaffold applications. Acta Biomaterialia, 6: (2010) p. 4596-4604.

8. Gupta, P, Tenhundfeld, G, Daigle, E and Ryabkov, D, Electrolytic plasma technology: Science and engineering - An overview. Surf. Coat. Techn., 201: (2007) p. 8746-8760.

9. $\mathrm{Gu}, \mathrm{WC}, \mathrm{Lv}, \mathrm{GH}$, Chen, H, Chen, GL, Feng, WR and Yang, SZ, PEO protective coatings on inner surface of tubes. Surf. Coat. Techn., 201: (2007) p. 6619-6622.

10. Yao, Z, Jiang, J, Jia, F, Jiang, Z and Wang, F, Growth characteristics of plasma electrolytic oxidation ceramic coatings on Ti-6Al-4V alloy. Applied Surface Science, 254: (2008) p. 40844091.

11. Matykina, E, Arrabal, R, Skeldon, P and Thompson, GE, Investigation of the growth processes of coatings formed by AC plasma electrolytic oxidation of aluminium. Electrochimica Acta, 54: (2009) p. 6767-6778.

12. Dunleavy, CS, Golosnoy, IO, Curran, JA and Clyne, TW, Characterisation of discharge events during plasma electrolytic oxidation. Surf. Coat. Techn., 203: (2009) p. 3410-3419.

13. Curran, JA and Clyne, TW, Thermo-physical Properties of Plasma Electrolytic Oxide Coatings on Aluminium. Surf. Coat. Techn., 199: (2005) p. 168-176.

14. Curran, JA and Clyne, TW, The Thermal Conductivity of Plasma Electrolytic Oxide Coatings on Aluminium and Magnesium. Surf. Coat. Techn., 199: (2005) p. 177-183.

15. Curran, JA and Clyne, TW, Porosity in Plasma Electrolytic Oxide Coatings. Acta Materialia, 54: (2006) p. 1985-1993.

16. Duocel® Aluminum Foam Brochure. 1998, ERG, INC., Oakland, CA.

17. Lindquist, WB and Venkatarangan, A, Investigating 3D Geometry of Porous Media from High Resolution Images. Physics and Chemistry of the Earth Part A: Solid Earth and Geodesy, 24: (1999) p. 593-599.

18. Tan, JC and Clyne, TW, Ferrous Fibre Network Materials for Noise Reduction in Gas Turbine Aeroengines, Part II: Thermomechanical Stability. Adv. Eng. Mater., 10: (2008) p. 201-209. 


\section{Figure Captions}

Fig.1 Schematic depiction of the loading arrangement and specimen geometry used for compressive testing.

Fig.2 (a) X-ray tomographic visualisation and (b) derived segmented strut structure of a "Duocel” foam, prior to PEO treatment.

Fig.3 Distributions of (a) strut length and (b) inclination of strut axes to a reference direction, together with that for an ideal isotropic sample. These plots were compiled from data relating to four samples.

Fig.4 Secondary electron images of the surface of a PEO treated sample having a conversion fraction, $f_{\text {con }}$, of 0.272 .

Fig.5 Backscattered mode SEM images of typical strut cross-sections for samples with conversion fraction values, $f_{\text {con }}$ of (a) 0.293, (b) 0.412 and (c) 0.540.

Fig.6 Experimental data for the conversion fraction, $f_{\text {con, }}$ of various specimens, (a) as obtained by weighing before and after PEO processing, plotted as a function of the processing time, and (b) comparing values obtained for the same specimens by weighing and by image analysis of strut sections, based on a metal density of $2.7 \mathrm{Mg} \mathrm{m}^{-3}$ and two different values for the density of the ceramic.

Fig.7 Experimental stress-strain curves for compressive loading of specimens subjected to different PEO processing times, exhibiting different conversion fraction values.

Fig.8 Experimental stress-strain curves for tensile loading of specimens subjected to different PEO processing times, exhibiting different conversion fraction values.

Fig.9 Plot of the fracture energy exhibited during tensile loading, as a function of the conversion fraction of the specimen concerned. 


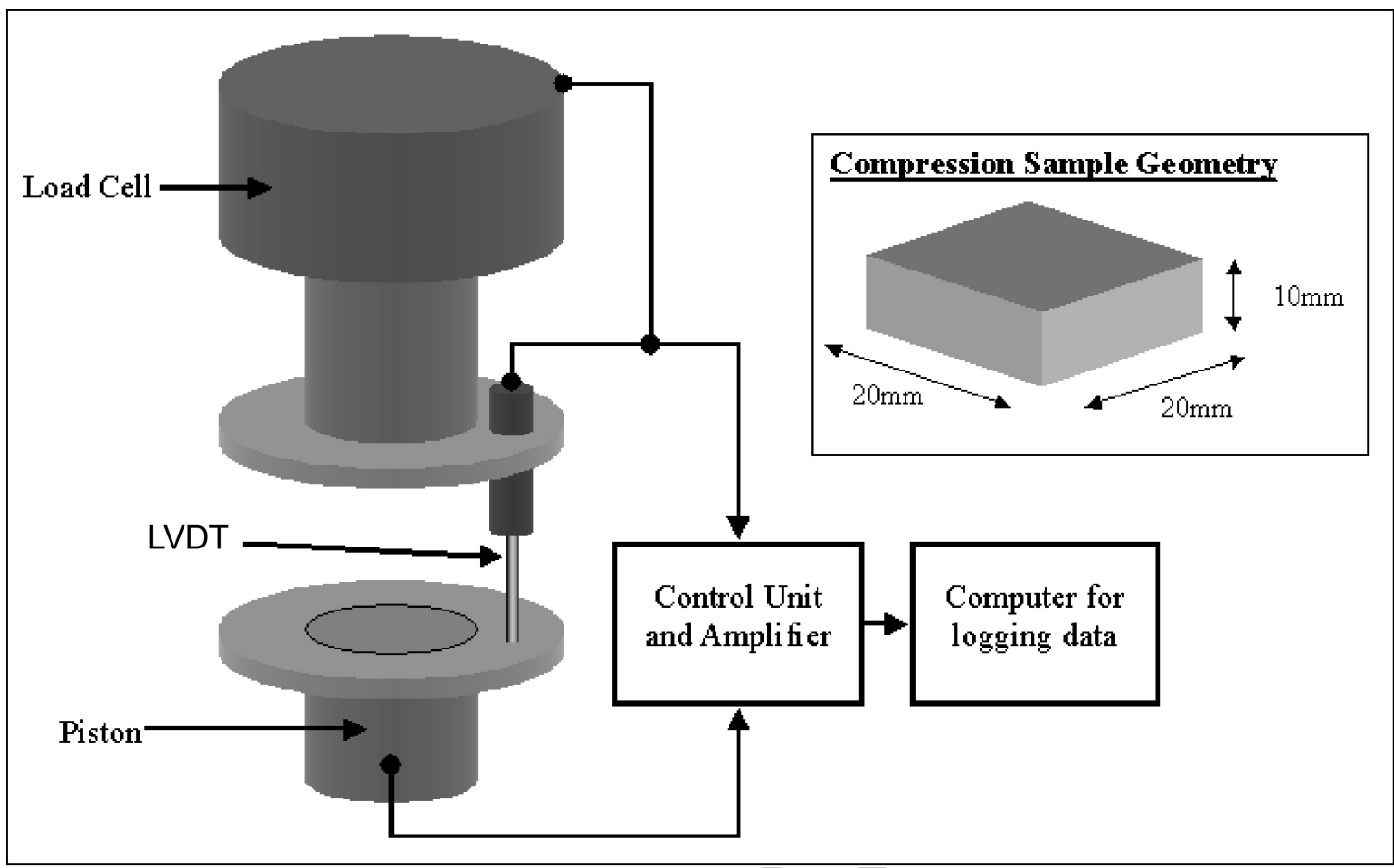



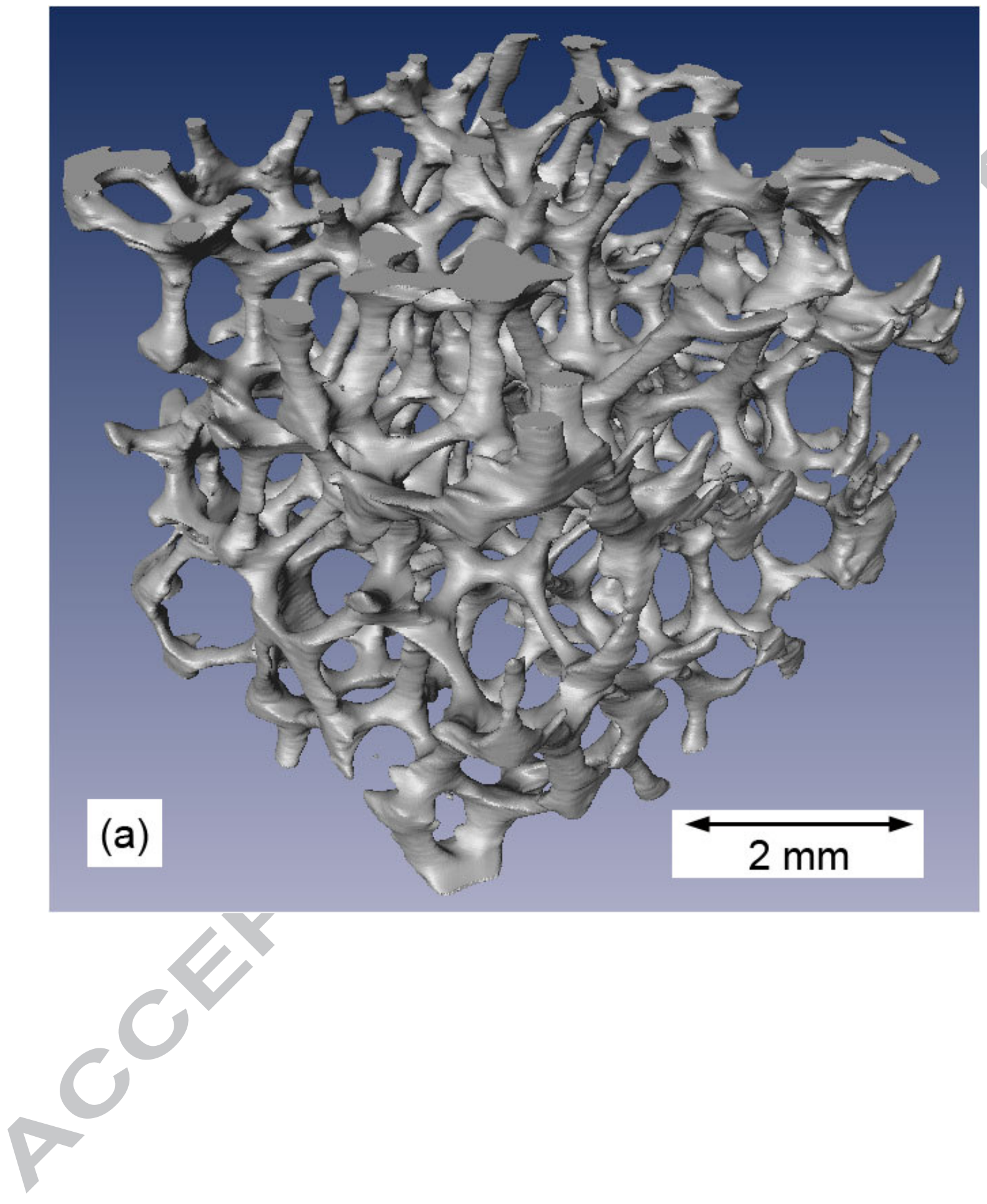


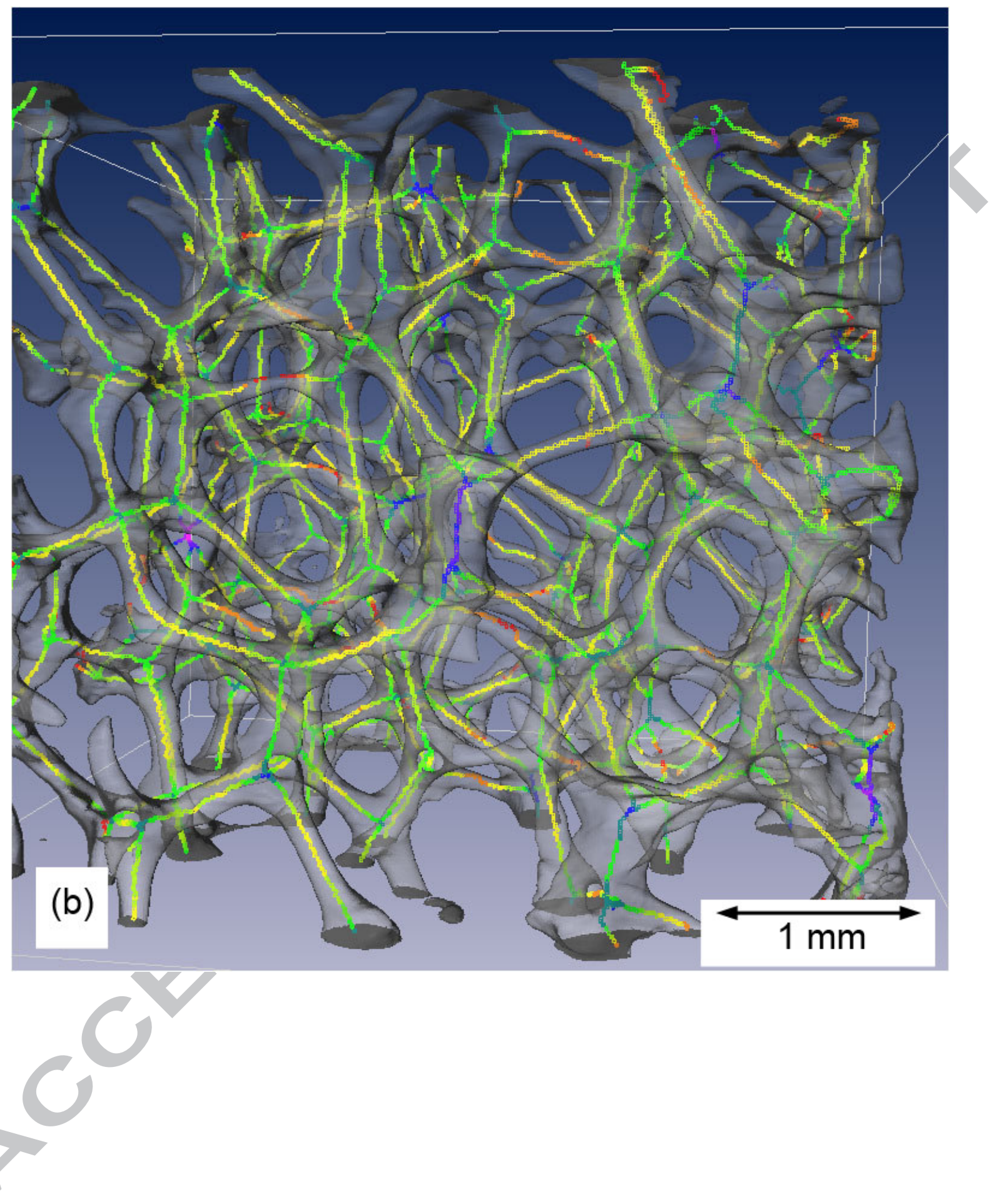




\section{ACCEPTED MANUSCRIPT}

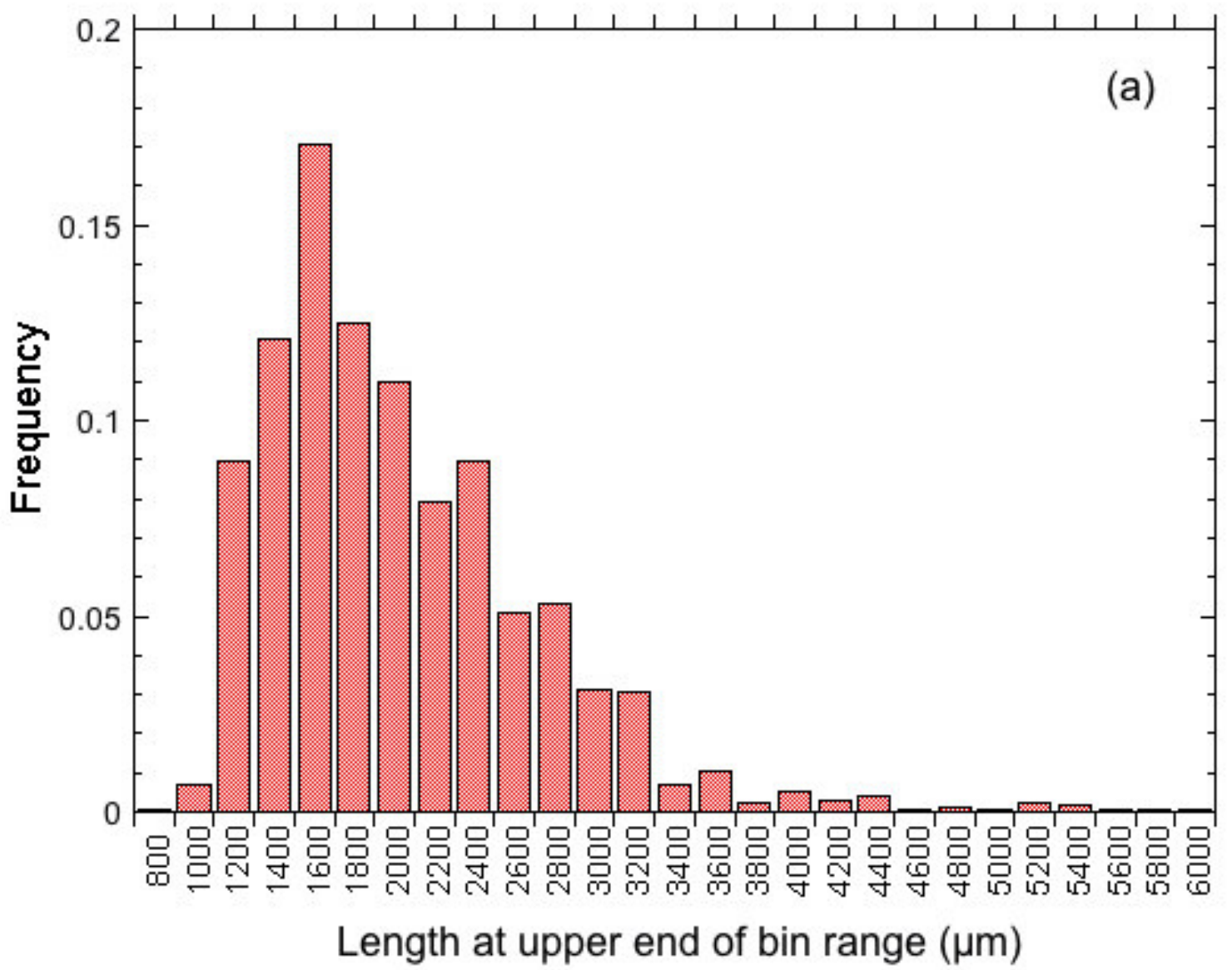




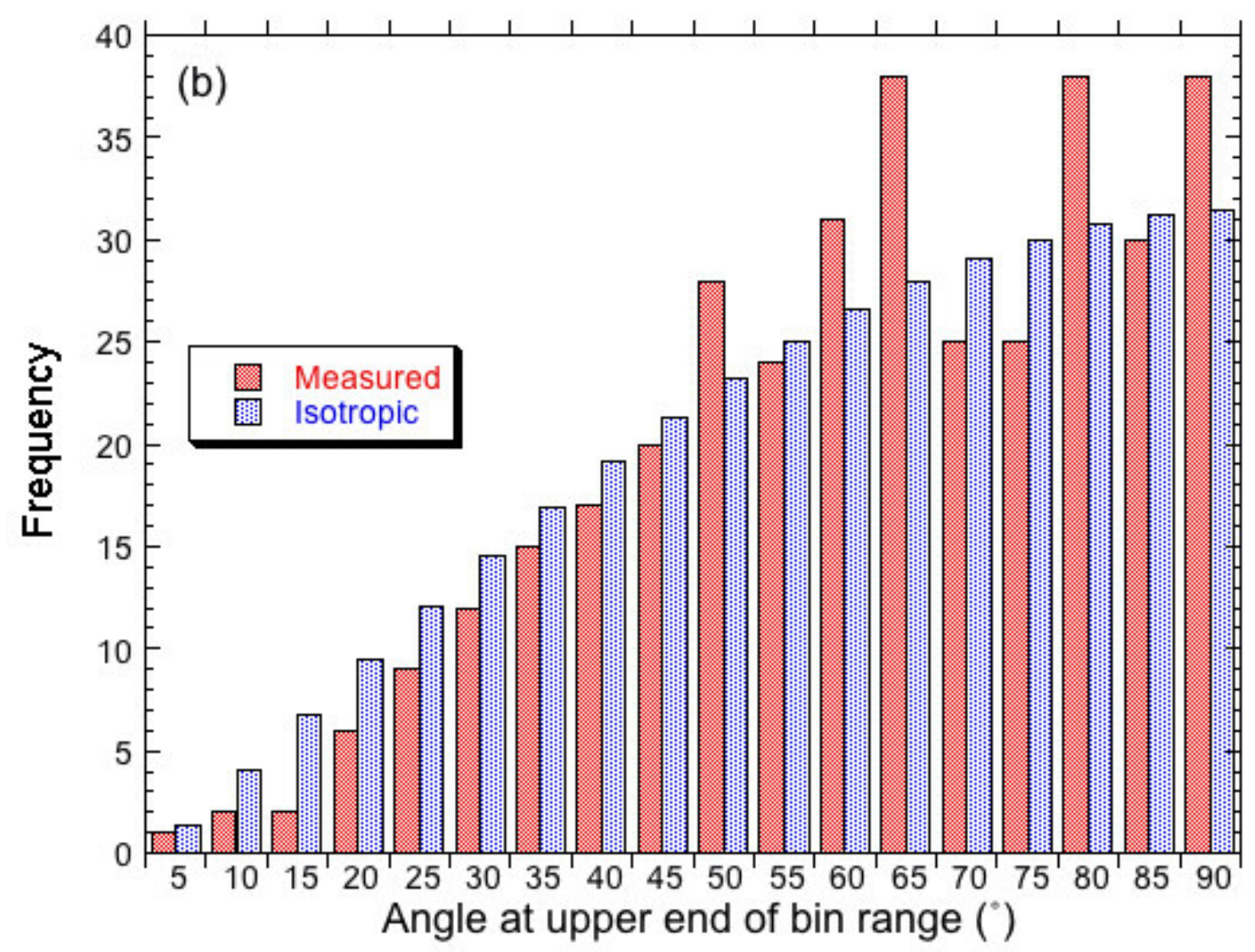




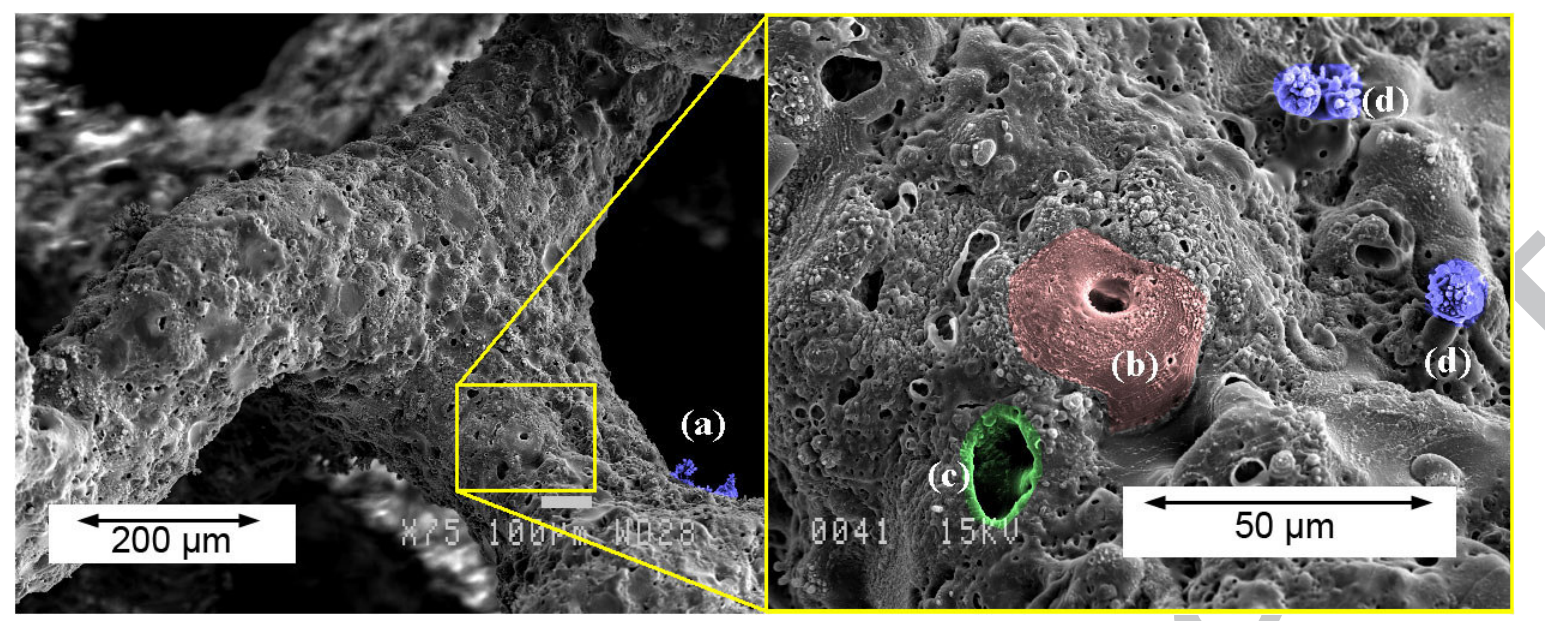




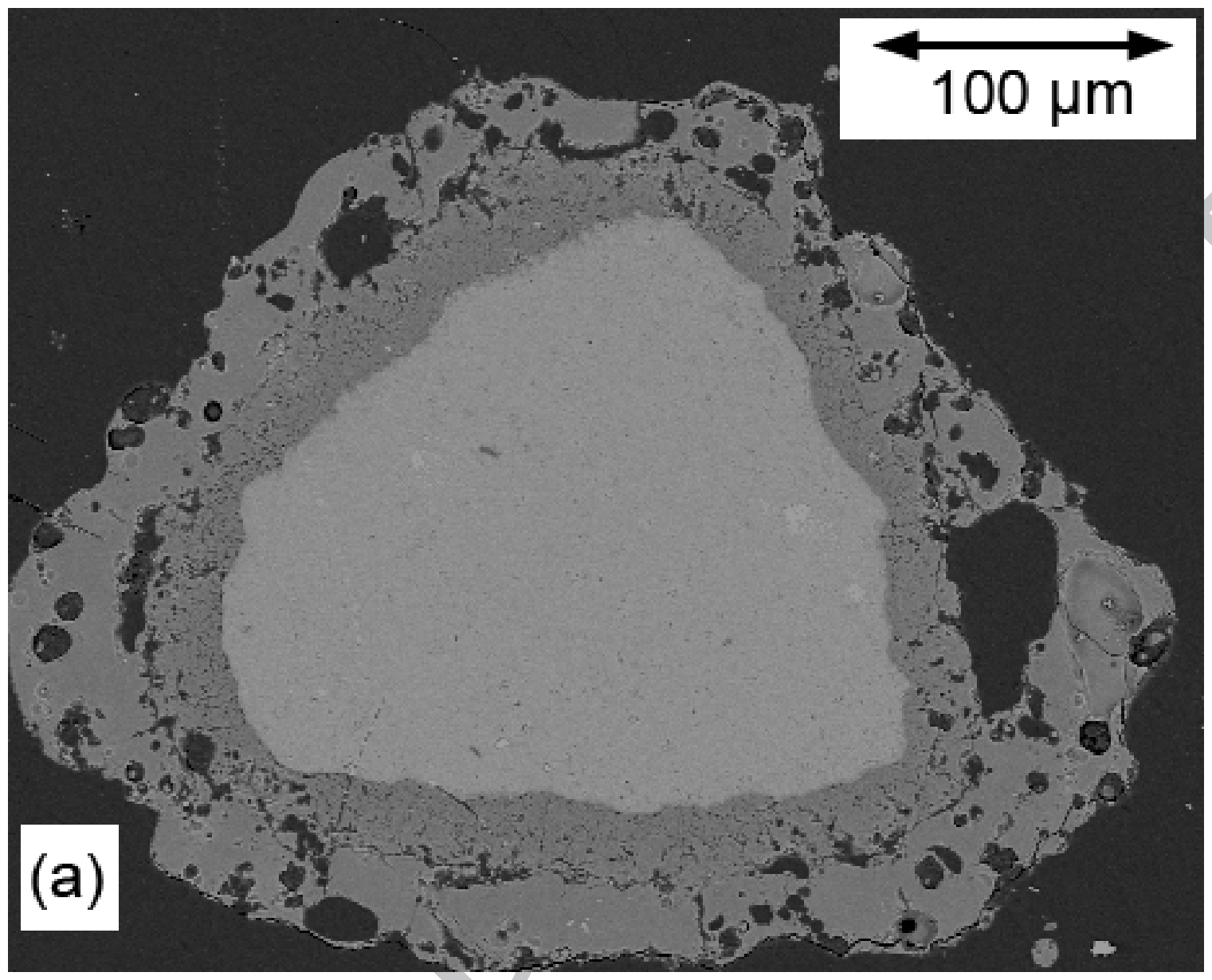




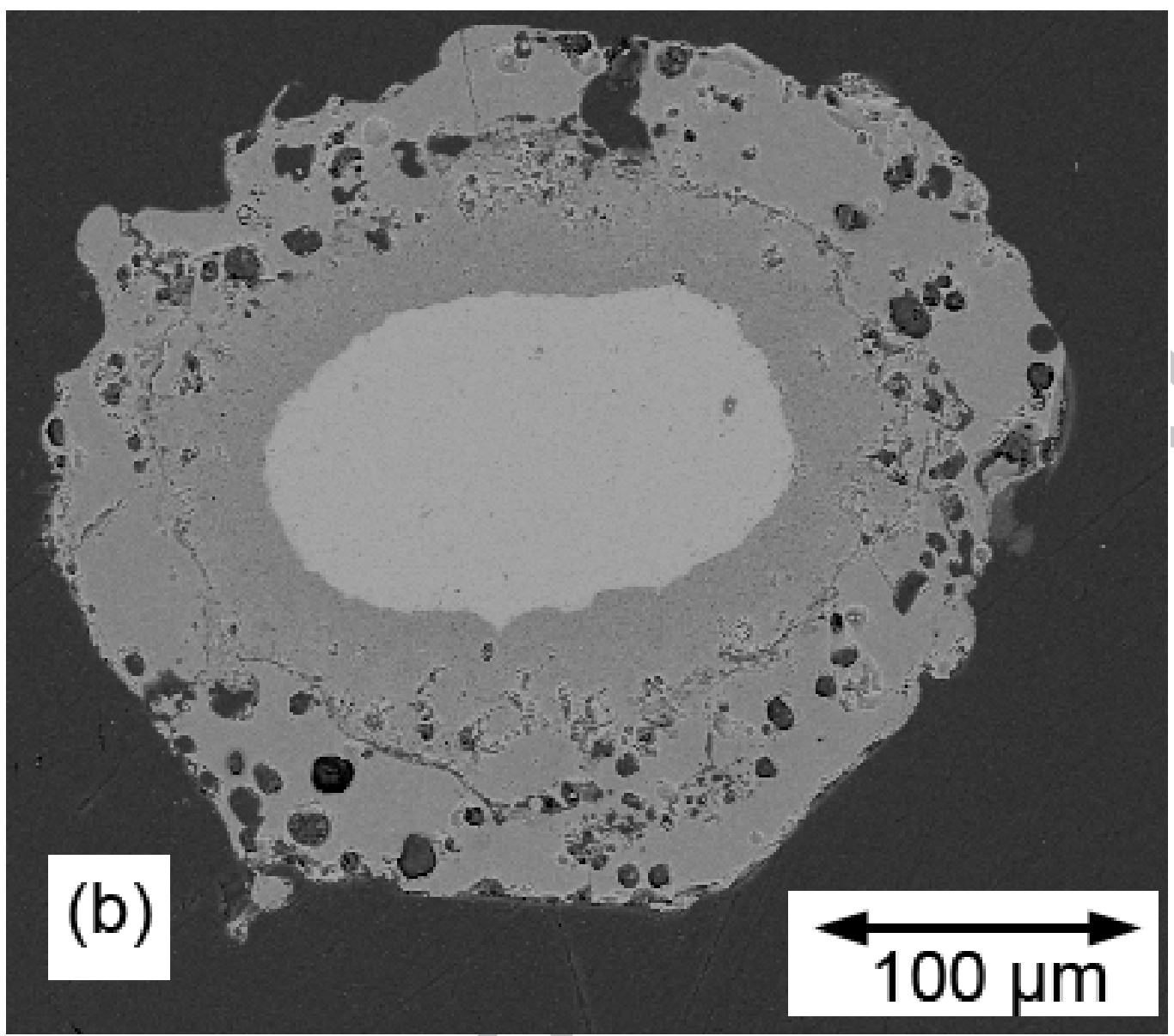




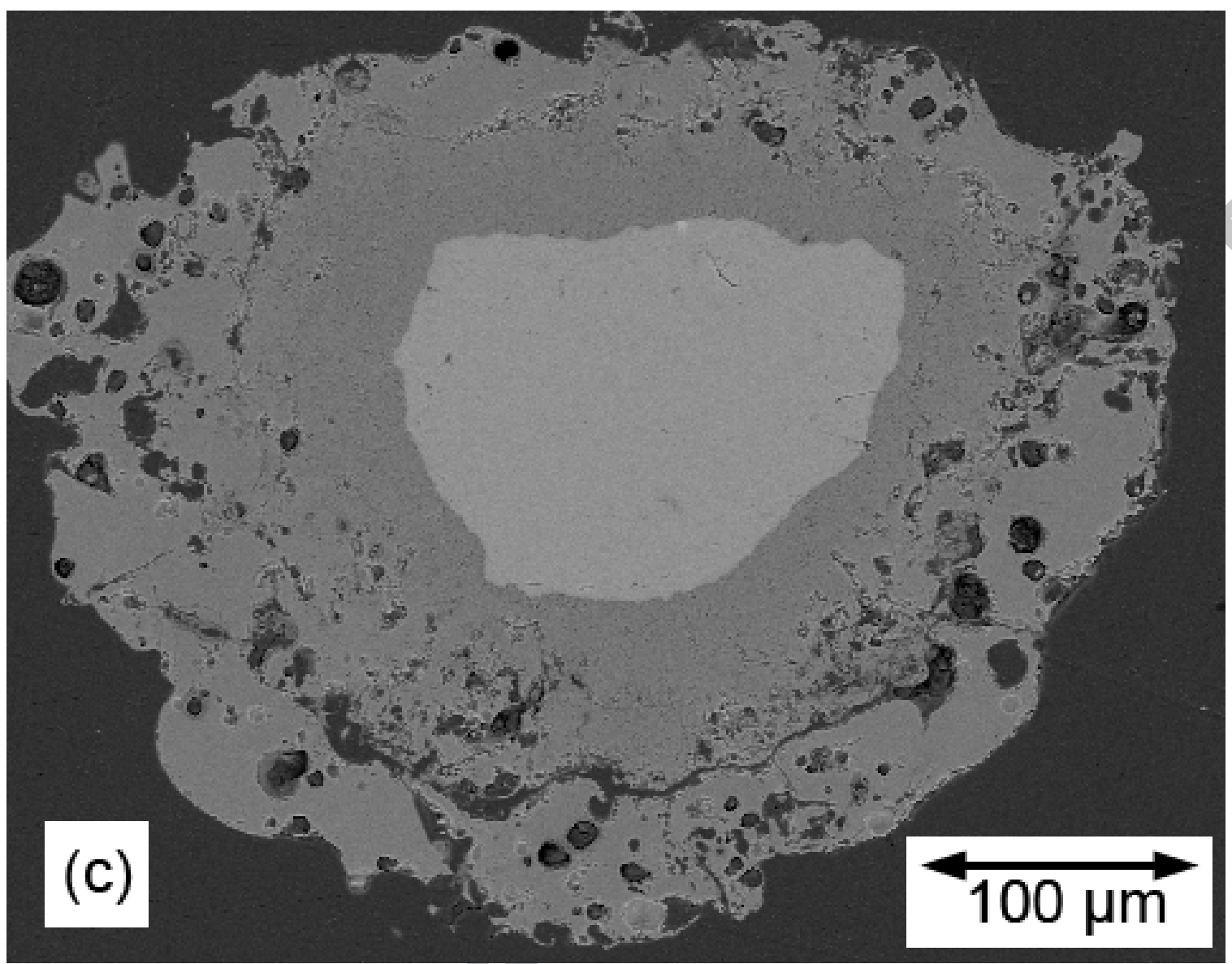




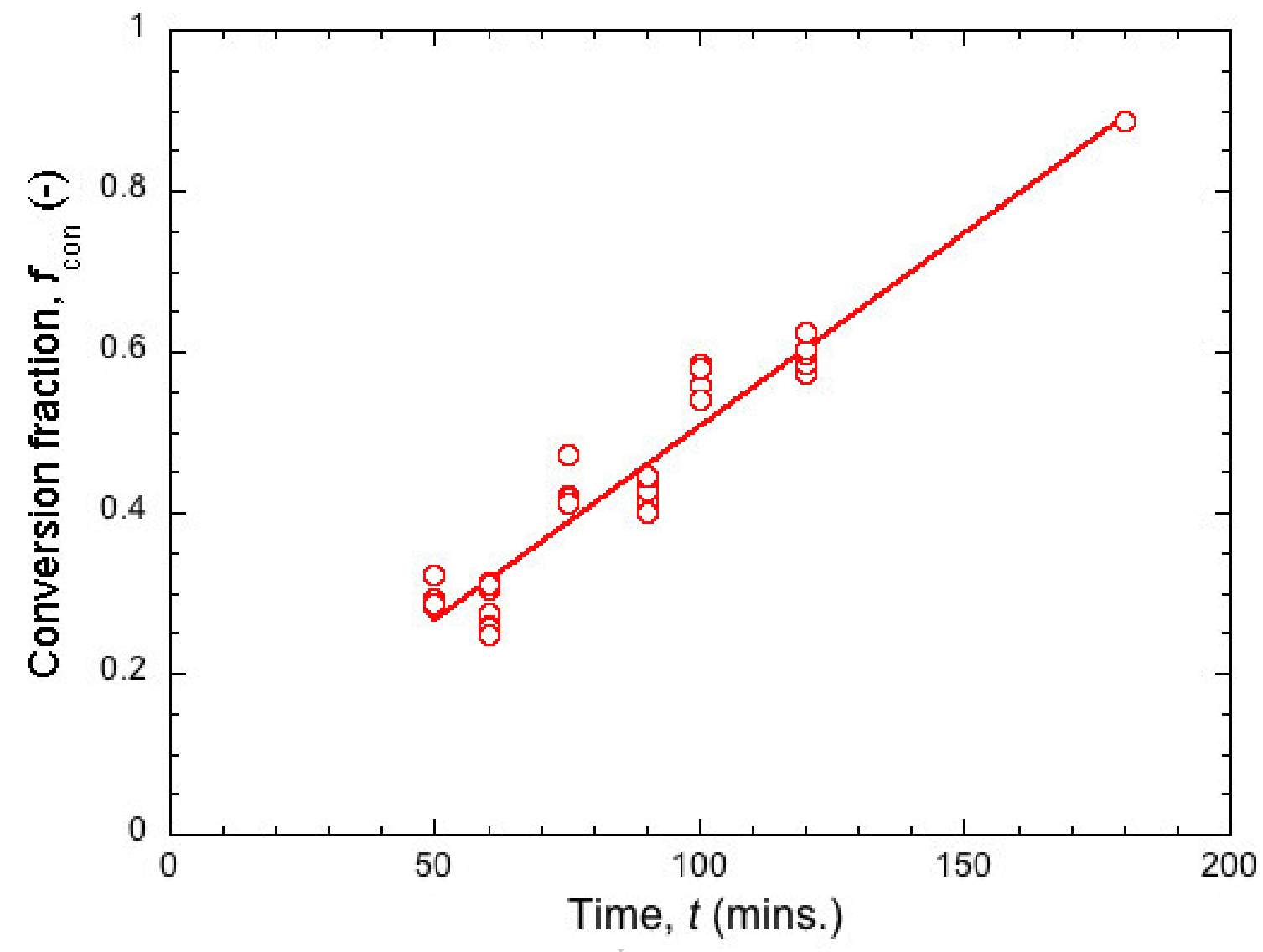




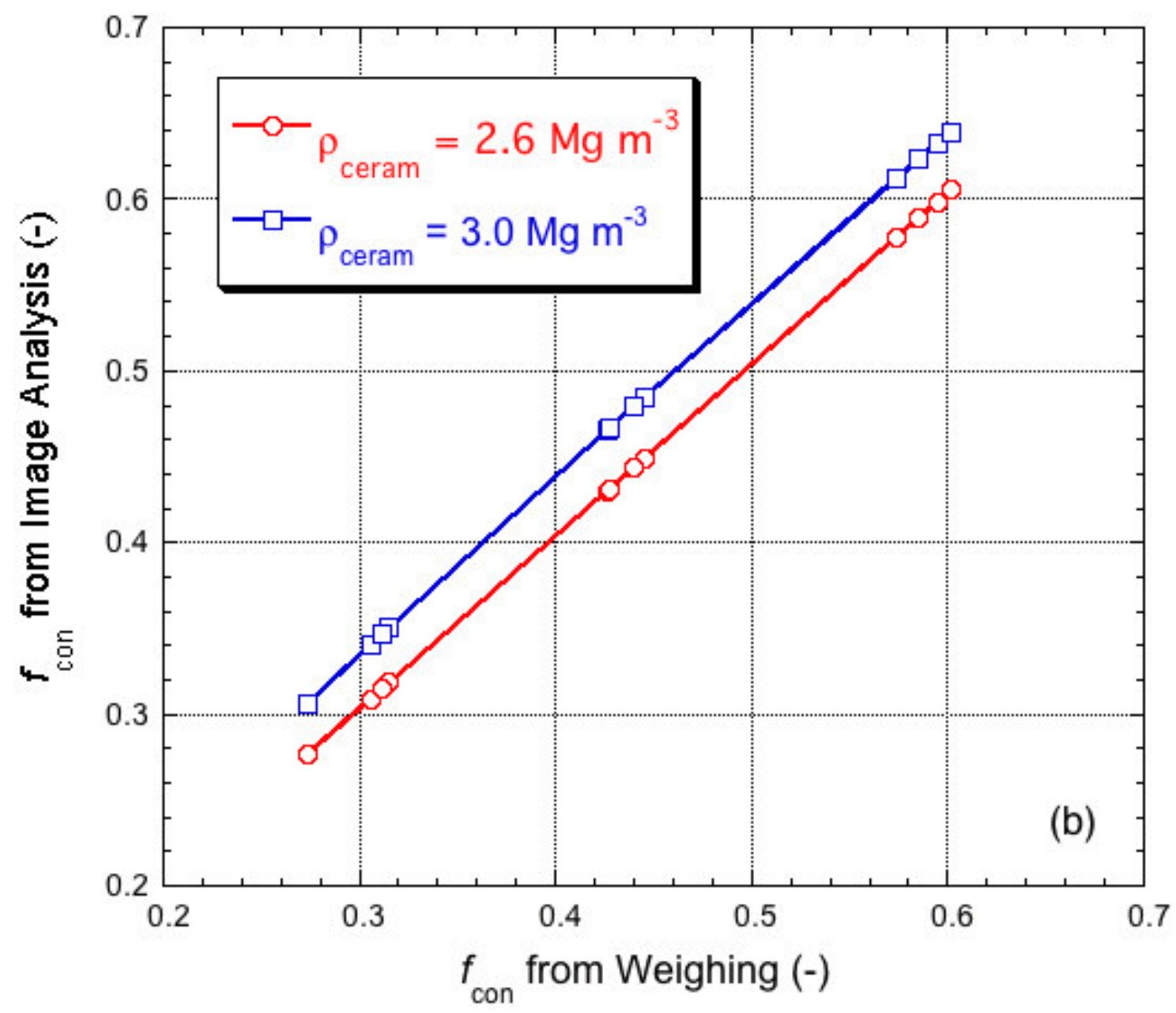




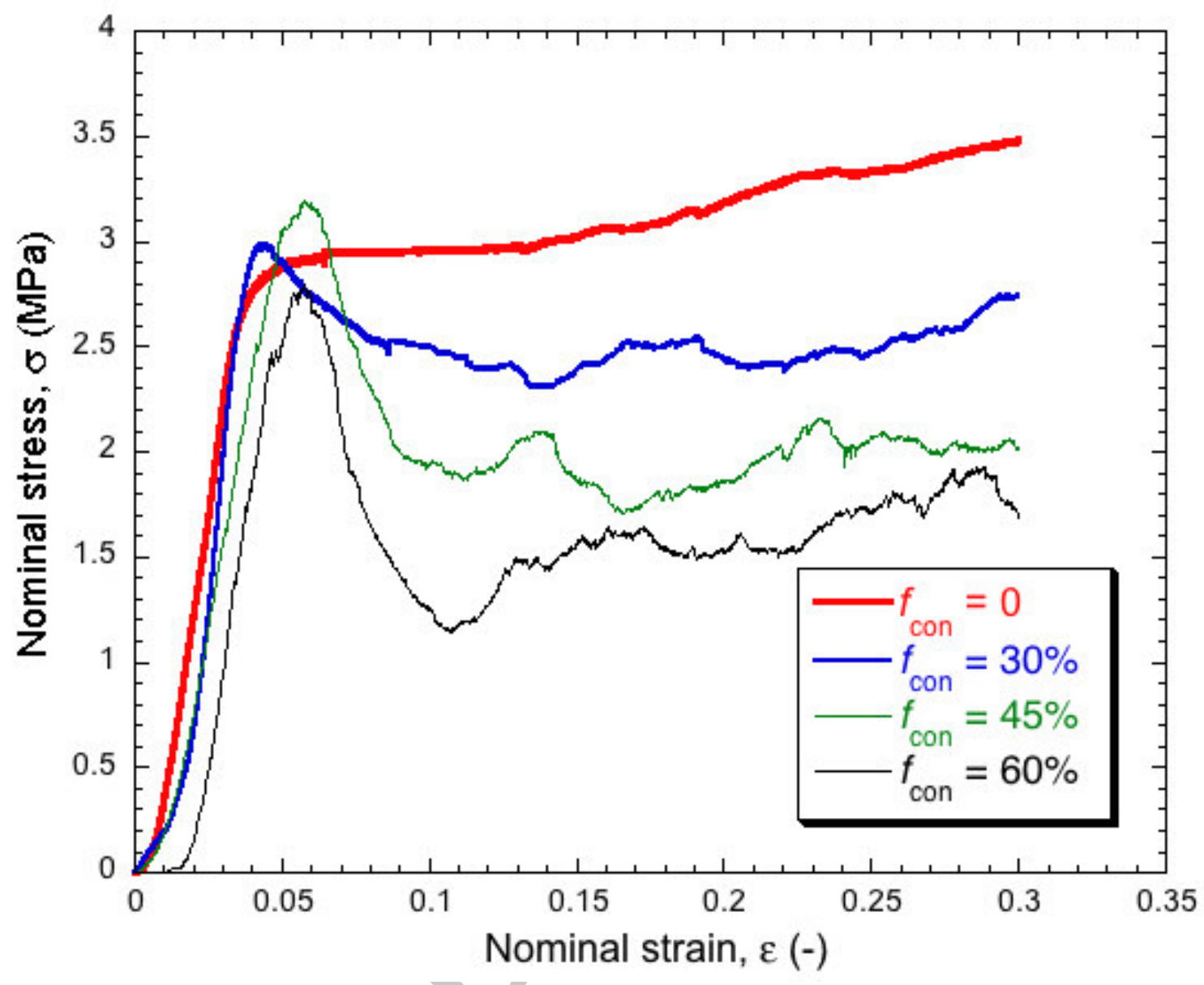




\section{ACCEPTED MANUSCRIPT}

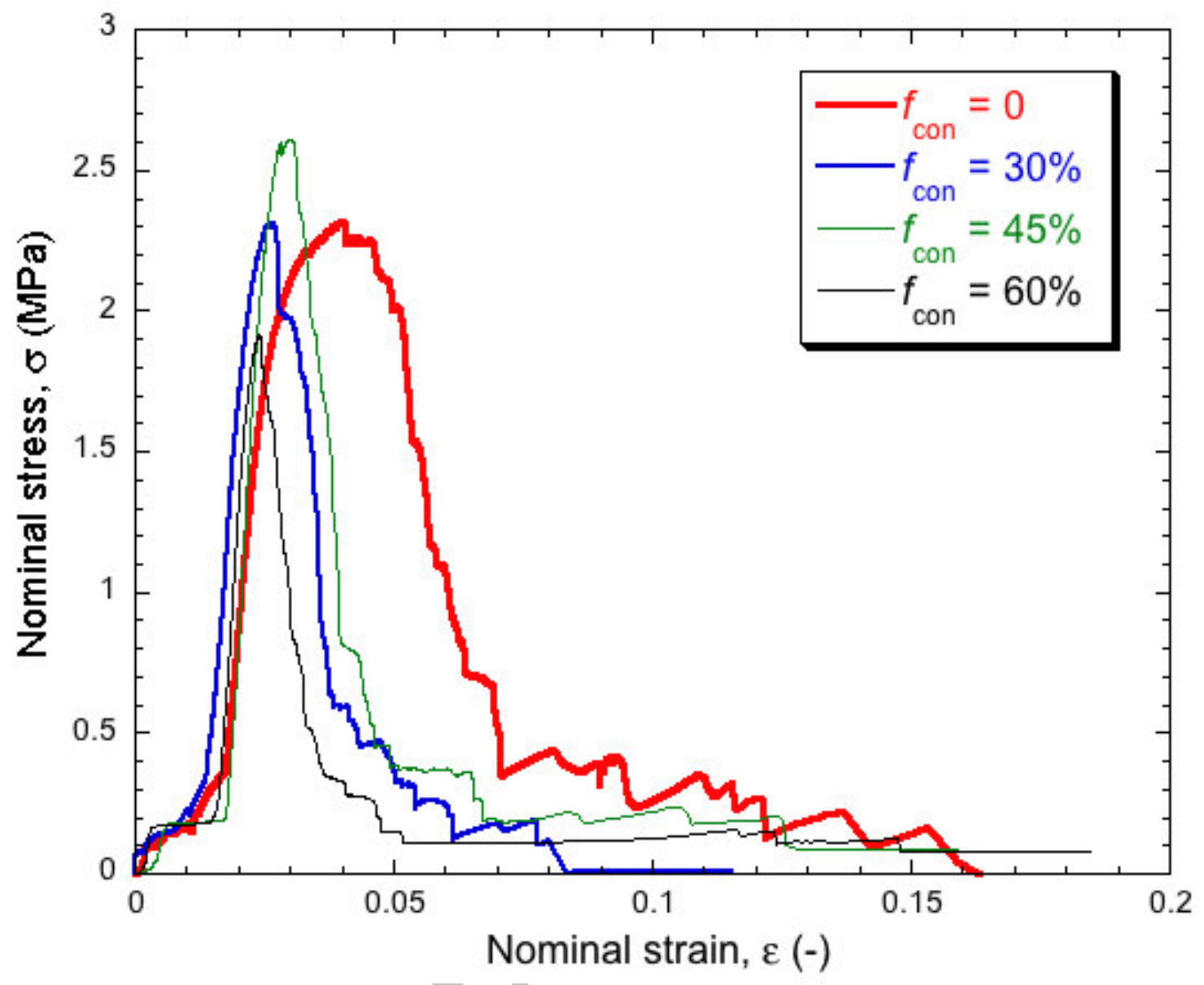


ACCEPTED MANUSCRIPT

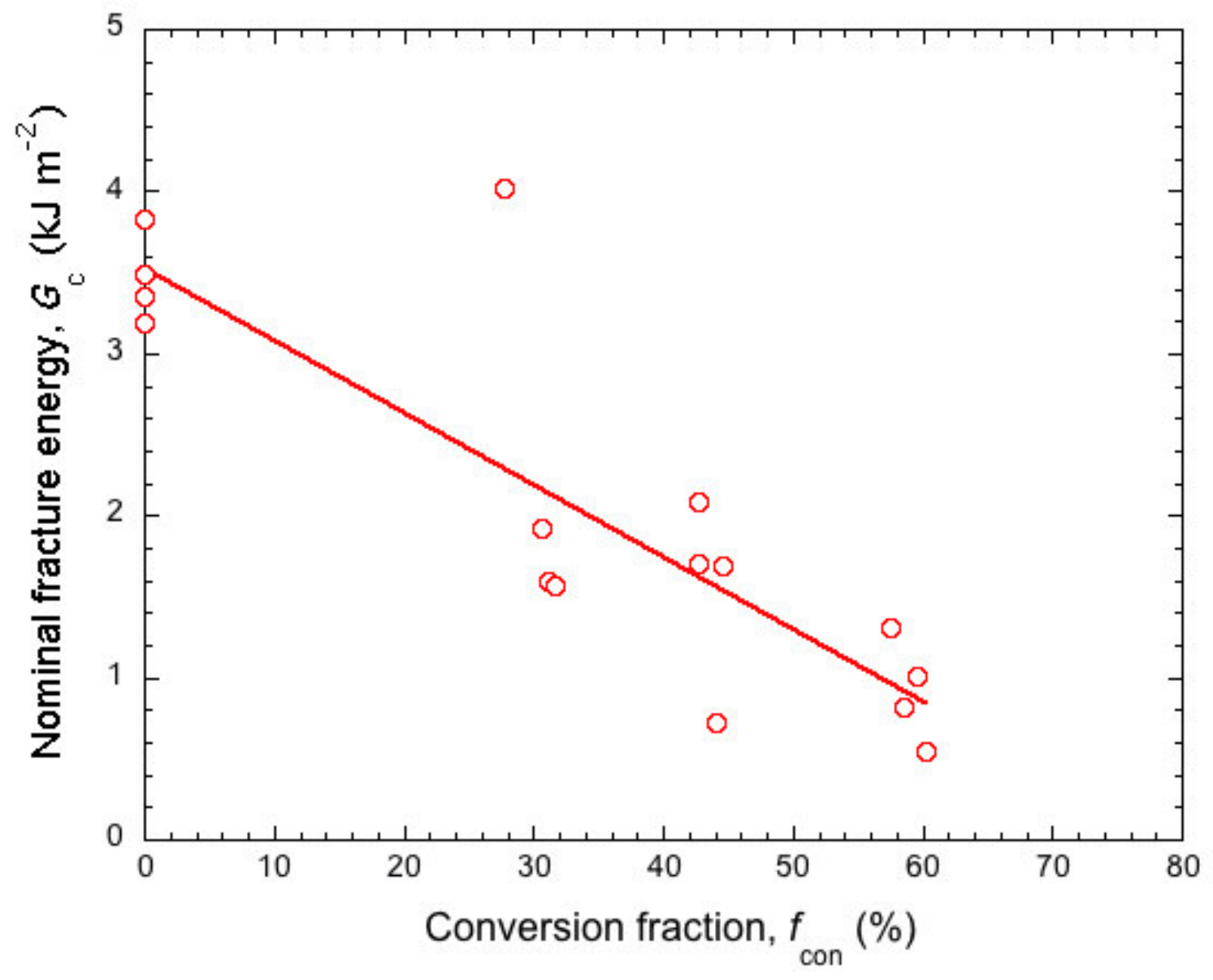

